\title{
On Design of Fatigue Resistance Metallic Parts
}

\author{
Strain Posavljak ${ }^{1)}$
}

\begin{abstract}
This paper is devoted to design of metallic parts exposed to low cycle fatigue. Two flat discs, as representatives of these parts, were discussed. The first with 8 , and the second with 64 eccentrically arranged holes. Their resistance to low cycle fatigue was investigated. Cyclic properties of two aerospace steels nominated for workmanship, plus planned revolves per minute and revolves per minute of $5 \%$ above planned, are taken into account. On the base of estimated low cycle fatigue life data, good design solution was discovered. On the other hand, it was shown that the both mentioned dises would have a large drop of resistance to low cycle fatigue for revolves per minute of $5 \%$ above planned.
\end{abstract}

Key words: flat discs, low cycle fatigue, good design solution.

\section{Introduction}

$\mathrm{T}$ HERE are many metallic parts of machine systems that are required to have satisfying fatigue resistance. Among them are certainly the compressor and turbine disks of aircraft engines, in which resistance to low cycle fatigue (LCF) is important.

Required resistance to LCF of certain disk, or its required low cycle fatigue life (LCFL), can be achieved by good combination assigned geometry, a material chosen for workmanship, and the load level. During assigning of geometry, a designer should devote attention to the stressed areas, as which are rims, hubs and holes of different purposes, in which, to a greater or lesser extent, local plastic strains can be provoked.

This time, the holes of different purposes, their size, number and arrangement, are interesting for us. Here's why. The aircraft accident described in [1] had occurred because of the crack initiation and fracture in the area of holes of one JTD8-15 engine compressor disk. Because of stressed holes of fractured fan disk of the left engine, of aircraft MD-88, occurred accident described in [2]. In the papers [3], [4] and [5], it is discovered that areas with holes are the most stressed areas of analyzed aircraft engine disks.

Useful conclusions regarding the design of fatigue-resistant aircraft engine disks, which will have holes of different purposes, can be drawn from discussing of flat disks.

Here we will discuss two flat disks with eccentrically arranged holes, and we will follow them under the basic marks D1 and D2.

Everything, what we will say, it will be a supplement to the research described in [6] and [7].

\section{Case of the flat disks}

\section{Geometries of disks}

The flat disks D1 and D2 with their geometries are shown in Fig.1.

Both disks have the same thicknesses $(20 \mathrm{~mm})$.

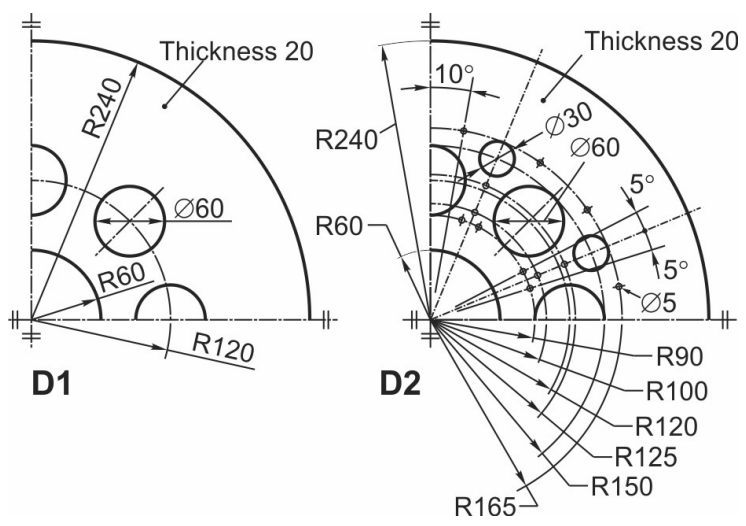

Figure 1. Geometries of the flat disks D1 and D2

The flat disk D1 has the central hole with radius R60 and eight eccentrically arranged holes $\varnothing 60$. The centers of these holes lay on the circular R120.

Beside of central hole and eight eccentrically arranged holes $\varnothing 60$, the flat disk D2 has eight eccentrically arranged holes $\varnothing 30$ whose centers lay on the circular R150, and fortyeight holes $\varnothing 5$ whose centers belong to circulars R90, R100, R125 and R165 (total 64 eccentrically arranged holes).

\section{Materials}

Two steels nominated for workmanship of our flat disks are: steel 13H1 1N2V2MF (Steel S1) and steel AISI 304 (Steel S2). Poisson's coefficients of these steels are the same $(v=$ 0.29 ), while their mass densities are different and amount:

$$
\rho(S 1)=7820 \mathrm{~kg} / \mathrm{m}^{3} \text { and } \rho(S 2)=7900 \mathrm{~kg} / \mathrm{m}^{3}
$$

Cyclic properties of steels S1 and S2 are included in Table 1 .

The estimation of the resistance to LCF, or estimation of LCFL of metallic parts, is based on the application of the next three equations:

\footnotetext{
Presented as Paper 054 at the $9^{\text {th }}$ International Scientific Conference on Defensive Technologies, Belgrade, Serbia, 15-16 October 2020

1) University of Banja Luka, Faculty of Mechanical Engineering, Banja Luka
}

Correspondence to: Strain Posavljak, e-mail: strain.posavljak@mf.unibl.org 


$$
\begin{aligned}
& \frac{\Delta \varepsilon}{2}=\frac{\Delta \sigma}{2 E}+\left(\frac{\Delta \sigma}{2 K^{\prime}}\right)^{\frac{1}{n^{\prime}}} \\
& \Delta \varepsilon=\frac{\Delta \sigma}{E}+2\left(\frac{\Delta \sigma}{2 K^{\prime}}\right)^{\frac{1}{n^{\prime}}} \\
& \frac{\Delta \varepsilon}{2}=\frac{\sigma_{f}^{\prime}}{E} N_{f}^{b}+\varepsilon_{f}^{\prime} N_{f}^{c}
\end{aligned}
$$

Table 1. Cyclic properties of steels S1 and S2

\begin{tabular}{||c|c|c||}
\hline \multicolumn{1}{|c|}{ Property } & \multicolumn{2}{|c||}{ Value } \\
\hline \hline Modulus of elasticity, $E[\mathrm{MPa}]$ & Steel S1 [6] & Steel S2 [8] \\
\hline Cyclic strength coefficient, $K^{\prime}[\mathrm{MPa}]$ & 110682.0 & 190000.0 \\
\hline Cyclic strain hardening exponent, $n^{\prime}$ & 0.118 & 2275.0 \\
\hline Fatigue strength coefficient, $\sigma^{\prime} f[\mathrm{MPa}]$ & 1818.8 & 0.334 \\
\hline Fatigue strength exponent, b & -0.144 & -0.139 \\
\hline Fatigue ductility coefficient, $\varepsilon^{\prime} f$ & 0.5351 & 0.174 \\
\hline Fatigue ductility exponent, $c$ & -0.6619 & -0.415 \\
\hline
\end{tabular}

The first equation in (1) is the equation of the cyclic stressstrain curve, the second presents Massing's curve, and the third is the equation of the basic strain-life curve [9]. These curves for the certain metallic material, we obtain by the testing of specimens in the controlled strains regime, when is $R=\varepsilon_{\min } / \varepsilon_{\max }=-1$, and the mean stress $\sigma_{m}=0$.

In the previous three equations, $\Delta \varepsilon / 2$ and $\Delta \sigma / 2$ are the half-ranges of strains and stresses, while $\Delta \varepsilon$ and $\Delta \sigma$ are corresponding ranges. $N_{f}$ is the number of cycles to failure (to crack initiation).

Equations in (1), for steel S1, have the next forms:

$$
\begin{aligned}
& \frac{\Delta \varepsilon}{2}=\frac{1}{206682}\left(\frac{\Delta \sigma}{2}\right)+\left[\frac{1}{1103}\left(\frac{\Delta \sigma}{2}\right)\right]^{\frac{1}{0.118}} \\
& \Delta \varepsilon=\frac{1}{206682}(\Delta \sigma)+2\left[\frac{1}{1103}\left(\frac{\Delta \sigma}{2}\right)\right]^{\frac{1}{0.118}} \\
& \frac{\Delta \varepsilon}{2}=8.799 \times 10^{-3} N_{f}^{-0.144}+0.5351 N_{f}^{-0.6619}
\end{aligned}
$$

For steel S2, the forms of those equations are:

$$
\begin{aligned}
& \frac{\Delta \varepsilon}{2}=\frac{1}{190000}\left(\frac{\Delta \sigma}{2}\right)+\left[\frac{1}{2275}\left(\frac{\Delta \sigma}{2}\right)\right]^{\frac{1}{0.334}} \\
& \Delta \varepsilon=\frac{1}{190000}(\Delta \sigma)+2\left[\frac{1}{2275}\left(\frac{\Delta \sigma}{2}\right)\right]^{\frac{1}{0.334}} \\
& \frac{\Delta \varepsilon}{2}=6.668 \times 10^{-3} N_{f}^{-0.139}+0.174 N_{f}^{-0.415}
\end{aligned}
$$

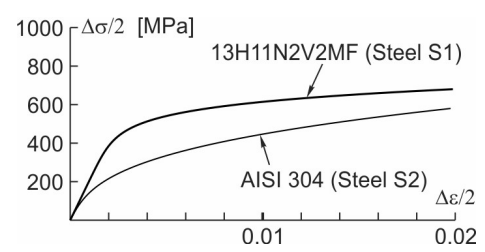

Figure 2. Cyclic stress-strain curves of steels S1 and S2

Cyclic stress-strain curves, Massing's curves and the basic strain-life curves of the steels $\mathrm{S} 1$ and $\mathrm{S} 2$ are shown in the next figures.

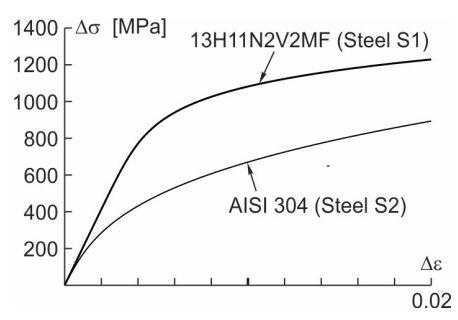

Figure 3. Massing's curves of steels S1 and S2

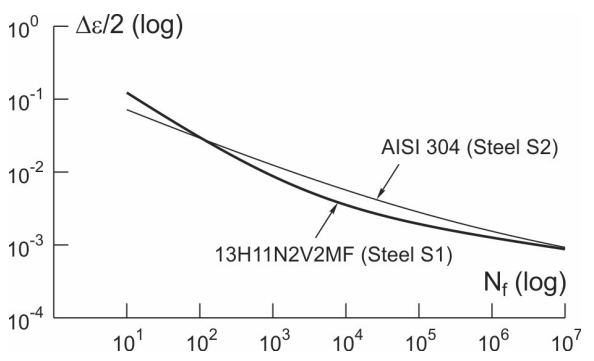

Figure 4. Basic strain-life curves of steels S1 and S2

According to materials nominated for the flat disks workmanship, to the basic marks D1 and D2, we will add S1 or S2, and practically we will have a job with four disks: D1S1, D1S2, D2S1 and D2S2.

\section{Loads}

Suppose that flat disks D1 and D2 will be loaded by own centrifugal forces provoked by imaginary spin tests ST1 and ST2, with diagrams included in Fig. 5.

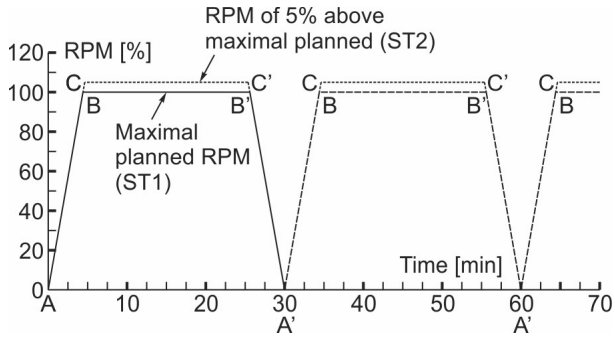

Figure 5. Diagrams of imaginary spin tests ST1 and ST2

In the spin test ST1, the first test block is $A-B-B^{\prime}-A^{\prime}$ and the other blocks are $A^{\prime}-B-B^{\prime}-A^{\prime}$ with maximal planned revolves per minute (RPM) $15000(100 \%)$. Similarly, for the spin test ST2 we have blocks $\mathrm{A}-\mathrm{C}-\mathrm{C}$ ' $-\mathrm{A}^{\prime}$ and $\mathrm{A}$ ' $-\mathrm{C}-\mathrm{C}$ ' $-\mathrm{A}^{\prime}$ with maximal RPM of 5\% above maximal planned, and it is $15750(105 \%)$. The quotient between 15750 RPM and 15000 RPM is 1.05 .

\section{Local stress-strain responses}

Local stress-strain responses of the flat disks D1 and D2 are connected with their critical points. If they loaded by own centrifugal forces, according to [6] and [7], the critical points will be points $P_{1}$ and $P_{2}$. Position of these points is identified in Fig 6. They belong to the contours of the holes $\varnothing 60$ and the circular R90.

The data on local stress responses, for the case of ideal elasticity (the data on linear stress responses at critical points of the flat disks), are contained in Table 2. In that table, we notice nominal stresses $\sigma_{n, i j}$ and maximal stresses $\sigma_{\max , i j}$. 
The index $j=1$ refers to disk $\mathrm{D} 1$ and its critical point $\mathrm{P}_{1}$, while the index $j=2$ refers to disk D2 and its critical point $\mathrm{P}_{2}$.
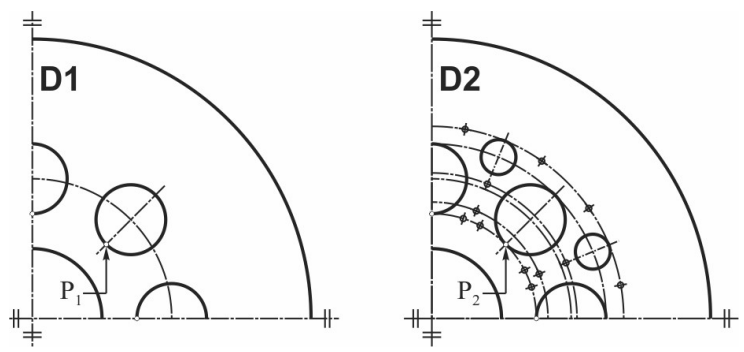

Figure 6. Position of critical points $\mathrm{P}_{1}$ and $\mathrm{P}_{2}$ on the flat disks D1 and D2

Stress values $\sigma_{\max , i j}$ were computed as follows:

$$
\sigma_{\max , i j}=K_{t, j} \sigma_{n, i j} \quad(i=1,2, \ldots, 8 / j=1,2)
$$

Theoretical or geometric stress concentration factors $K_{t, j}$ in (4) are taken from [6].

Table 2. The data on linear stress responses at critical points of the flat disks

\begin{tabular}{|c|c|c|c|c|c|c|}
\hline Disk & Spin test & $\mathrm{i}$ & $\mathrm{j}$ & $\begin{array}{c}\sigma_{\mathrm{n}, \mathrm{ij}} \\
{[\mathrm{MPa}]}\end{array}$ & $K_{\mathrm{t}, \mathrm{j}}$ & $\begin{array}{c}\sigma_{\text {max }, \mathrm{ij}} \\
{[\mathrm{MPa}]}\end{array}$ \\
\hline D1S1 & ST1 & 1 & \multirow{4}{*}{1} & 652.208 & \multirow{4}{*}{2.118} & 1381.377 \\
\hline D1S1 & ST2 & 2 & & 719.059 & & 1522.967 \\
\hline D1S2 & ST1 & 3 & & 658.880 & & 1395.508 \\
\hline D1S2 & ST2 & 4 & & 726.415 & & 1538.547 \\
\hline D2S1 & ST1 & 5 & \multirow{4}{*}{2} & 652.208 & \multirow{4}{*}{2.007} & 1308.981 \\
\hline D2S1 & ST2 & 6 & & 719.059 & & 1443.151 \\
\hline $\mathrm{D} 2 \mathrm{~S} 2$ & ST1 & 7 & & 658.880 & & 1322.372 \\
\hline D2S2 & ST2 & 8 & & 726.415 & & 1457.915 \\
\hline
\end{tabular}

The values of nominal stresses $\sigma_{n, i j}$ in Table 2, were obtained using the next expressions:

$$
\begin{aligned}
& \sigma_{n, 11}=\sigma_{n r}\left(\frac{R S_{r}}{R S}\right)^{2}=\sigma_{n, 52} \\
& \sigma_{n, 21}=1.05^{2} \sigma_{n, 11}=\sigma_{n, 62} \\
& \sigma_{n, 31}=\sigma_{n, 11} \frac{\rho(S 2)}{\rho(S 1)}=\sigma_{n, 72} \\
& \sigma_{n, 41}=1.05^{2} \sigma_{n, 31}=\sigma_{n, 82}
\end{aligned}
$$

and they are connected with all points that lay on the circular R90, of the flat disks without eccentrically arranged holes.

The reference nominal stresses $\sigma_{n r}$, in the first expression in (5), at critical points of flat disks D1S1 and D2S1, for the reference rotation speed $R S_{r}=16800 \mathrm{RPM}$, amounts: $\sigma_{n r}=818.13 \mathrm{MPa}[6]$. Here, for the same disks, rotation sped $R S=15000$ RPM .

Here is important to note that the stress values $\sigma_{\max , i j}$ are not real values. However, although they unreal, from the levels of these stresses, using Neuber's hyperbola [9] or some of its modification, as it as Sonsino-Birger's modification in [10] and [11], we can move to the level of real stress-strain response (nonlinear stress-strain response) at the critical points.

Nonlinear stress-strain response at the critical points of our flat disks, taking into account spin tests ST1 and ST2, was described by stabilized hysteresis loops which were modeled using corresponding Massing's curves of steels S1 and S2.
The upper points of the stabilized hysteresis loops were determined graphically (see [6]), as the intersection points between Sonsino-Birger's curves

$$
\begin{aligned}
& \frac{\Delta \varepsilon}{2}=\frac{1}{2} \frac{K_{t, j} \sigma_{n, i j}}{E_{j}}\left(\frac{K_{t, j} \sigma_{n, i j}}{\frac{\Delta \sigma}{2} E_{j}}+1\right) \\
& (i=1,2, \ldots, 8 / j=1,2)
\end{aligned}
$$

and cyclic stress-strain curves defined by the first equations in (2) and (3). Coordinates of the i-th intersection point are: $(\Delta \varepsilon / 2)_{i}$ and $(\Delta \sigma / 2)_{i}$. All these coordinates we have in Table 3 .

Table 3. Coordinates of upper points of stabilized hysteresis loops

\begin{tabular}{||c|c|c|c|c||}
\hline \hline Disk & Spin test & $\mathrm{i}$ & $(\Delta \varepsilon / 2)_{\mathrm{i}}$ & $(\Delta \sigma / 2)_{\mathrm{i}}[\mathrm{MPa}]$ \\
\hline \hline D1S1 & ST1 & 1 & 0.01076712 & 621.690 \\
\hline D1S1 & ST2 & 2 & 0.01250489 & 636.139 \\
\hline D1S2 & ST1 & 3 & 0.01379287 & 506.385 \\
\hline D1S2 & ST2 & 4 & 0.01574510 & 532.586 \\
\hline D2S1 & ST1 & 5 & 0.00992109 & 613.683 \\
\hline D2S1 & ST2 & 6 & 0.01151185 & 628.176 \\
\hline D2S2 & ST1 & 7 & 0.01282519 & 492.414 \\
\hline D2S2 & ST2 & 8 & 0.01463500 & 517.989 \\
\hline
\end{tabular}

Dimensions $\left(\Delta \varepsilon_{i} \times \Delta \sigma_{i}\right)$ of the stabilized hysteresis loops were obtained graphically also, as the interaction point coordinates between the second forms of Sonsino-Birger's curves

$$
\begin{aligned}
& \Delta \varepsilon=\frac{1}{2} \frac{K_{t, j} \Delta \sigma_{n, i j}}{E_{j}}\left(\frac{K_{t, j} \Delta \sigma_{n, i j}}{\Delta \sigma E_{j}}+1\right) \\
& (i=1,2, \ldots, 8 / j=1,2)
\end{aligned}
$$

and the second equations in (2) and (3). For our imaginary tests ST1 and ST2 Sonsino-Birger's curves in (6) and (7), coincide. Values for $K_{t, j}$ and $\sigma_{n, i j}=\Delta \sigma_{n, i j}$ in them are taken from Table 2. Values of modulus elasticity $E_{j}, j=1$ of steel $\mathrm{S} 1$ and modulus elasticity $E_{j}, j=2$ of steel $\mathrm{S} 2$, are taken form Table 1 .

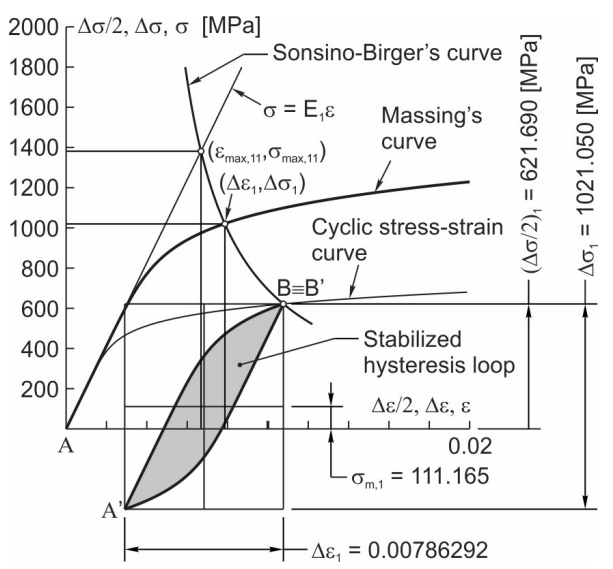

Figure 7. Graphically determined nonlinear stress-strain response at the critical point of disk D1S1 (spin test ST1)

For example, graphically determined nonlinear stress-strain responses at critical points of disks D1S1 and D1S2, for spin test ST1 and ST2, that defined by stabilized hysteresis loops, are shown in Fig. 7 and Fig. 8.

The intersection points between Sonsino-Birger's curves in 
(6) and lines

$$
\sigma=E_{j} \varepsilon, \quad(j=1,2)
$$

define local stress response of the flat disks, for the case of ideal elasticity (linear stress response).

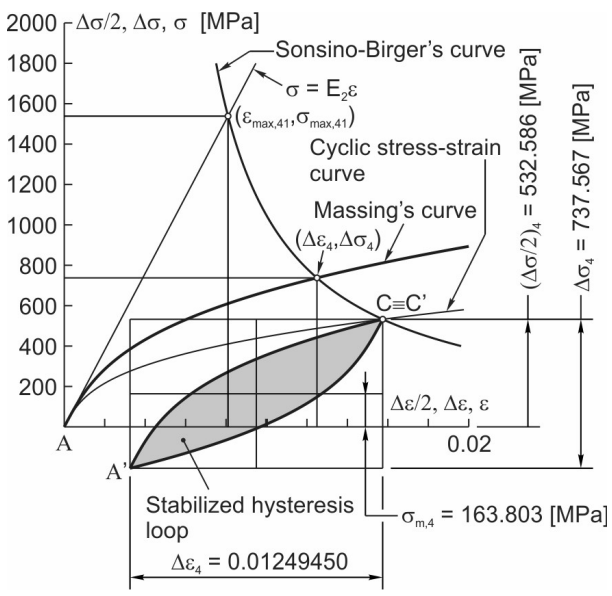

Figure 8. Graphically determined nonlinear stress-strain response at the critical point of disk D1S2 (spin test ST2)

All data on nonlinear stress-strain responses at critical points of the flat disks are included in Table 4.

Table 4. The data on nonlinear stress-strain responses at critical points of the flat disks

\begin{tabular}{||c|c|c|c|c|c||}
\hline \hline Disk & Spin test & $\mathrm{i}$ & $\begin{array}{c}\sigma_{\mathrm{mi}} \\
{[\mathrm{MPa}]}\end{array}$ & $\begin{array}{c}\Delta \sigma_{\mathrm{i}} \\
{[\mathrm{MPa}]}\end{array}$ & $\Delta \varepsilon_{\mathrm{i}}$ \\
\hline \hline D1S1 & ST1 & 1 & 111.165 & 1021.050 & 0.00786292 \\
\hline D1S1 & ST2 & 2 & 108.125 & 1056.028 & 0.00899770 \\
\hline D1S2 & ST1 & 3 & 156.971 & 698.827 & 0.01100589 \\
\hline D1S2 & ST2 & 4 & 163.803 & 737.567 & 0.01249450 \\
\hline D2S1 & ST1 & 5 & 113.286 & 1000.792 & 0.00730842 \\
\hline D2S1 & ST2 & 6 & 109.683 & 1036.985 & 0.00834991 \\
\hline D2S2 & ST1 & 7 & 153.352 & 678.122 & 0.01026591 \\
\hline D2S2 & ST2 & 8 & 159.990 & 715.999 & 0.01164870 \\
\hline
\end{tabular}

Fatigue resistance estimation and results discussion

Fatigue resistance estimation or LCFL estimation of the flat disks was carried out using Morrow's strain-life curve, that is defined in [9], and given in the general form:

$$
\frac{\Delta \varepsilon}{2}=\frac{\sigma_{f}^{\prime}-\sigma_{m}}{E} N_{f}^{b}+\varepsilon_{f}^{\prime} N_{f}^{c}
$$

This curve takes into account the influence of mean stress $\sigma_{m}$ and it presents a modification of the basic strain-life curve in (1).

By graphically solving of the four systems of equations,

$$
\begin{aligned}
& \frac{\Delta \varepsilon}{2}=\frac{1818.8-\sigma_{m, i}}{206682} N_{f}^{-0.144}+0.5351 N_{f}^{-0.6619} \\
& \frac{\Delta \varepsilon}{2}=\frac{\Delta \varepsilon_{i}}{2}, \quad i=1,2,3,4
\end{aligned}
$$

we obtained the first four data for $N_{f}=N_{f i}=L C F L_{i}$.

Similarly, by graphically solving the next four systems of equations

$$
\begin{aligned}
\frac{\Delta \varepsilon}{2} & =\frac{1267-\sigma_{m, i}}{190000} N_{f}^{-0.139}+0.174 N_{f}^{-0.415} \\
\frac{\Delta \varepsilon}{2} & =\frac{\Delta \varepsilon_{i}}{2}, \quad i=5,6,7,8
\end{aligned}
$$

we obtained the second four data for $N_{f}=N_{f i}=L C F L_{i}$.

The first equations in the system (10) and (11) are equations of Morrow's strain-life curves which refer on steels $\mathrm{S} 1$ and $\mathrm{S} 2$. The values for $\sigma_{m, i}$ and $\Delta \varepsilon_{i}$, in them, were taken from Table 4.

Results of estimated fatigue resistance, or estimated LCFL, expressed in test blocks of the spin tests ST1 and ST2, are contained in Table 5.

Table 5. Results of estimated LCFL

\begin{tabular}{||c|c|c|c||}
\hline Disk & Spin test & $i$ & LCFL $_{\mathrm{i}}[$ Test blocks] \\
\hline \hline D1S1 & ST1 & 1 & 6519 \\
\hline D1S1 & ST2 & 2 & 4525 \\
\hline D1S2 & ST1 & 3 & 9610 \\
\hline D1S2 & ST2 & 4 & 6555 \\
\hline D2S1 & ST1 & 5 & 8026 \\
\hline D2S1 & ST2 & 6 & 5524 \\
\hline D2S2 & ST1 & 7 & 11893 \\
\hline D2S2 & ST2 & 8 & 8091 \\
\hline
\end{tabular}

Graphically determined LCFL of disks D1S1 and D1S2 exposed to spin test ST1, we have in Fig. 9.

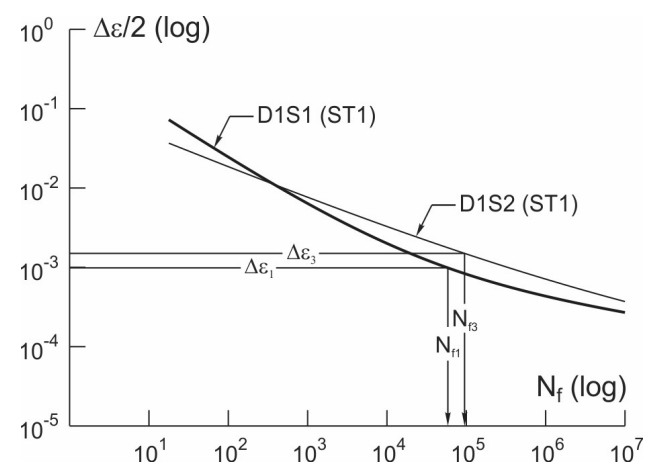

Figure 9. Graphically determined LCFL of disks D1S1 and D1S2 exposed to spin test ST1

The data on estimated LCFL are shown by histogram in Fig. 10 .

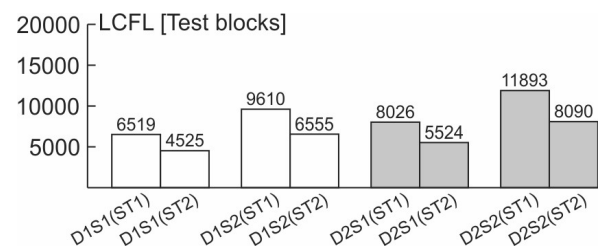

Figure 10. Histogram of data on estimated LCFL

For the same disks, in the case of their exposure to the spin test ST2, the resistance to LCF decreases, compared to the resistance to LCF in the case of exposure to the spin test ST1 (30.588\% for disk D1S1, 31.790\% for disk D1S2, 31.174\% for disk D2S1 and 31.977\% for disk D2S2).

Disk D1S2 has better resistance to LCF than disk D1S1 (47.415\% for the case of spin test ST1 and $44.862 \%$ for the case of spin test ST2). Similarly, disk D2S2 has better resistance to LCF than disks D2S1 (48.181\% for the case of spin test ST1 and $46.452 \%$ for the case of spin test ST2).

Disk D2S1 has better resistance to LCF than disk D1S1 (23.117\% for the case of spin test ST1 and $22.077 \%$ for the case of spin test ST2).

Disk D2S2 has better resistance to LCF than disk D1S2 (23.757\% for the case of spin test ST1 and $23.417 \%$ for the case of spin test ST2). 


\section{Conclusion}

If we had a request to replace disk D1S1 with a new disk that would be overloaded by $5 \%$ above the planned load and would have LCFL at least $20 \%$ longer, we would conclude that we could replace it with disk D2S2. Because this disk is discovered as a good design solution.

The parts of machines, exposed to LCF, should not be forced, because with a small percentage increase in load, in a much higher percentage, their fatigue resistance can be reduced.

If it is necessary to overload the machine part exposed to LCF, then it is necessary to start with its redesigning. It is necessary to change its geometry or choose a new material for its workmanship, or both.

In the future research it would be interesting to carry out experimental spin tests for discussed flat disks and obtained results of LCFL compare with here estimated.

On the other hand, it would be interesting, through the boundary conditions, simulate the action of centrifugal forces of rims and blades of aircraft engine compressor and turbine discs, and investigate their influence on LCFL of flat disks that here were discussed.

The methodology of the fatigue resistance estimation of the flat disks with eccentrically arranged holes, can be applied and for the other metallic parts.

\section{References}

[1] Hall, J., Francis, R., Hammerschmidt, J., Goglia, J., Black, G., Aircraft Accident Report - Uncontained Engine Failure/Fire, ValuJet Airlines Flight 597 Douglas DC-9-32, N908VJ, Atlanta, Georgia, Jun 8, 1995, Report No. NTSB/AAR-96/03, 1996.
[2] Hall, J., Francis, R., Hammerschmidt, J., Goglia, J., Black, G., Aircraft Accident Report - Uncontained Engine Failure, Delta Air Lines Flight 1288 McDonnell Douglas MD-88, N927DA, July 6, 1996, Report No. NTSB/AAR-98/01, 1998

[3] Beres, W., Koul, A. K., "Stress Intensity Factor Calculations for Cracks Emanating from Bolt Holes in a Jet Engine Compressor Disc", ICAS 2002 CD-ROM Proceedings, pp. 583.1-583.8.

[4] Spodniak, M., Klimko, M., Hocko, M., Zitek, P., "Low Cycle Fatigue Numerical Estimation of a High Pressure Turbine Disc for The AL-31F Jet Engine", EJB Web Conference, Volume 143, 2017, 5 pages.

[5] Christo, M., Badarinath, B. G., Skivakumar, S., Umesh, V., "Structural Design Research Through Finite Element Method (FEM) for a Compressor Disc", IJEAT, Volume-9 Issue-4, April 2020, pp. 475-481.

[6] Posavljak, S., Fatigue Life Investigation of Aero Engine Rotating Discs (in Serbian), Doctoral Dissertation, University of Belgrade, Faculty of Mechanical Engineering, 2008.

[7] Posavljak, S., Maksimovic, K., Boljanovic, S., "On Importance of Geometry and Cyclic Materials Properties in Design of Fatigue Resistant Turbojet Engine Rotating Disks", Proceedings of $11^{\text {th }}$ International DEMI 2013 scientific conference, pp. 169-178, University of Banja Luka, Faculty of Mechanical Engineering, $30^{\text {th }}$ May $-1^{\text {st }}$ Jun 2013

[8] "Technical Report on Low Cycle Fatigue Properties Ferrous and Nonferrous Materials", SAE J1099, REV. AUG2002.

[9] Bannantine, J. A., Comer, J., Handrock, J., Fundamentals of Material Fatigue Analysis, Prentice-Hall, Englewood Cliffs, New Jersey, 1990.

[10] Sonsino, C. M., "Zur Bewertung des Schwing-festigkeitsverhaltens von Bauteilen mit Hilifeort-licher Beanspruchungen", Konstruktion 45 (1993) 25-33.

[11] Birger, I. A., "Prognozirovanie resursa pri maloci-klovoj ustalosti", Problemy prochnosti, No 10, pp. 39-44, 1985.

Received: 15.07 .2020 Accepted: 01.09.2020

\title{
O projektovanju metalnih delova otpornih na zamor
}

\begin{abstract}
Ovaj rad je posvećen projektovanju metalnih delova izloženih malociklusnom zamoru. Razmatrana su dva ravna diska, kao predstavici ovih delova. Prvi sa 8 i drugi sa 64 ekscentrično raspoređena otvora. Istražena je njihova otpornost na malociklusni zamor. Uzete su u obzir ciklične karakteristike za dva vazduhoplovna čelika kandidovana za izradu, plus planirani obrtaji u minuti i obrtaji u minuti od 5\% iznad planiranih. Na osnovu podataka o procenjenom malociklusnom zamornom veku, otkriveno je dobro projektno rešenje. S druge strane, pokazano je da bi oba pomenuta diska imala veliki pad otpornosti na malociklusni zamor za brojeve obrtaja od $5 \%$ iznad planiranih.
\end{abstract}

Ključne reči: ravni diskovi, malociklusni zamor, dobro projektno rešenje. 